\title{
A segunda fórmula da autoconsciência: o 'como' da consciência de si na Doutrina da Ciência nova methodo
}

\section{Christian Klotz}

\author{
(2) OpenEdition \\ Journals \\ Edição electrónica \\ URL: https://journals.openedition.org/ref/1872 \\ DOI: $10.4000 /$ ref. 1872 \\ ISSN: 2258-014X \\ Editora \\ EuroPhilosophie Editions \\ Refêrencia eletrónica \\ Christian Klotz, «A segunda fórmula da autoconsciência: o 'como' da consciência de si na Doutrina da \\ Ciência nova methodo», Revista de Estud(i)os sobre Fichte [Online], 23 | 2021, posto online no dia 01 \\ dezembro 2021, consultado o 05 março 2022. URL: http://journals.openedition.org/ref/1872 ; DOI: \\ https://doi.org/10.4000/ref.1872
}

Este documento foi criado de forma automática no dia 5 março 2022

() EuroPhilosophie 


\title{
A segunda fórmula da autoconsciência: o 'como' da consciência de si na Doutrina da Ciência nova methodo
}

\author{
Christian Klotz
}

\section{NOTA DO AUTOR}

Revisão de Francisco Prata Gaspar.

\section{Apresentação}

No seu artigo de 1966 sobre o 'insight' originário de Fichte, Dieter Henrich analisa o desenvolvimento do pensamento fichtiano como sucessão de respostas diferentes a um problema filosófico que a autoconsciência apresenta. O problema consistiria no fato de que a explicação da autoconsciência como reflexão, que prima facie parece altamente plausível, não procede. Segundo esse modelo explicativo, na autoconsciência o sujeito volta-se para si mesmo, tornando-se objeto das suas representações ou pensamentos. Henrich denomina essa explicação da autoconsciência de "teoria da essência do eu como reflexão". ${ }^{1}$ Segundo Henrich, Fichte foi o primeiro a constatar que a explicação da autoconsciência como reflexão envolve um regresso infinito, argumento este que no artigo de 1966 é apresentado em duas versões. A apresentação dos regressos envolvidos na teoria da autoconsciência como reflexão dada por Henrich influenciou fortemente tanto o debate sobre a filosofia de Fichte, quanto a discussão sistemática sobre a autoconsciência. Isto pode ser dito particularmente a respeito da segunda versão do regresso, que é apresentada através do seguinte argumento: para que haja autoconsciência, não é suficiente que um sujeito de fato se torne objeto para si mesmo. 
O sujeito tem que saber também que seu objeto é idêntico com ele mesmo, o que pressupõe que o sujeito já possua algum tipo de autoconsciência. Desse modo, o modelo da autoconsciência como reflexão não explica a possibilidade da autoconsciência, mas em cada aplicação pressupõe que o sujeito já possua alguma consciência de si, o que gera um regresso infinito na explicação da autoconsciência. ${ }^{2}$ Posteriormente, Manfred Frank formulou o segundo argumento contra a teoria da autoconsciência como reflexão com base no "de-se constraint", isto é, no princípio de que a autoconsciência é essencialmente consciência de si mesmo como de si mesmo, não podendo ser explicado como mera autorrepresentação. ${ }^{3}$

2 Segundo Henrich, na segunda versão da Doutrina da Ciência Fichte apresenta uma explicação da autoconsciência cujo objetivo é justamente contemplar o elemento recognicional envolvido na autoconsciência. Nela, o eu é caracterizado através da fórmula: "o eu põe-se como se pondo". Segundo essa fórmula, a autoconsciência possui uma característica fundamental de qualquer saber: a de entender algo como algo. Henrich ressalta que Fichte exprime essa característica da autoconsciência na segunda exposição da Doutrina da Ciência ao utilizar a distinção kantiana entre intuição e conceito: no conhecimento, um objeto dado numa intuição é entendido como algo através de um conceito, e no caso da autoconsciência é justamente o componente conceitual que possibilita ao sujeito entender uma autorrepresentação ou -intuição sua como representação de si. ${ }^{4}$

3 Com sua leitura da segunda fórmula da autoconsciência em Fichte, Henrich chamou atenção para um elemento central da segunda versão da fundamentação fichtiana da filosofia, a Doutrina da Ciência nova methodo. Nos primeiros parágrafos dessa exposição, Fichte de fato defende a tese de que a autoconsciência essencialmente possui a característica de ser uma consciência de si 'como algo', e tal tese possui um papel chave na explicação da estrutura da consciência que nela é desenvolvida. Qual é o entendimento fichtiano do assim entendido 'como' da autoconsciência? Essa será a questão central deste artigo. Defender-se-á a tese de que a exposição fichtiana possui uma complexidade que vai além da leitura apresentada por Henrich. É verdade que a fórmula fichtiana "O eu põe-se como se pondo", focalizada por Henrich, possui um papel central na explicação fichtiana dos aspectos teóricos e práticos da consciência a partir da egoidade. No entanto, mostrar-se-á que ela diz respeito a uma forma secundária da autoconsciência que já envolve a estrutura da reflexão na qual o eu se torna objeto para si mesmo. Segundo a tese central deste artigo, a concepção fundamental da autoconsciência defendida por Fichte na segunda versão da Doutrina da Ciência envolve a ideia de um 'como' pré-reflexivo que ainda não é propriamente conceitual. Por isso, defenderemos que a ideia do 'como não-objetual' da autoconsciencia é uma noção fundamental da segunda exposição da Doutrina da Ciência. Para desenvolver essa tese, cabe relacionar a posição de Fichte com a distinção kantiana entre autoconsciência e autoconhecimento. Pois ela pode ser entendida como desdobramento sistemático dessa distinção que norteia a crítica kantiana da psicologia racional na Crítica da Razão Pura. Por isso, voltamo-nos primeiro para a concepção kantiana de autoconsciência e autoconhecimento. 


\section{0 'como' não-objetual da autoconsciência originária em Kant}

4 Ao referir-se à autoconsciência como 'apercepção pura', Kant tematiza a consciência de si em sentido específico e claramente definido: trata-se daquela autoconsciência na qual estamos conscientes de nós mesmos como "inteligência e sujeito pensante" Segundo Kant, a consciência de si como sujeito pensante é a autoconsciência 'originária' que possibilita a autoatribuição de representações sem a qual as representações não poderiam ser minhas. ${ }^{6} \mathrm{Na}$ medida em que a autoconsciência originária é um princípio unificador dos conteúdos da consciência, ela é a chave para a demonstração da necessidade do uso das categorias como regras fundamentais da 'síntese', isto é, da atividade unificadora que possibilita qualquer conhecimento. Já na dedução transcendental das categorias, em cujo foco está a ligação intrínseca entre a autoconsciência assim entendida e a unidade sintética das representações, Kant ressalta uma consequência negativa da sua concepção da autoconsciência originária: mesmo que tal autoconsciência possibilite e até torne necessária a nossa relação cognitiva com objetos, ela por si não pode ser considerada um conhecimento. Essa tese torna-se o ponto central na crítica kantiana dos paralogismos da psicologia racional que, segundo a análise kantiana, buscam estabelecer conclusões acerca do eu como objeto substancial a partir de aspectos da autoconsciência originária.

5 Como Kant justifica sua tese da diferença entre a autoconsciência originária e o conhecimento de si? Na dedução transcendental das categorias, Kant aponta para um argumento que focaliza o conteúdo peculiar da autoconsciência originária: tal autoconsciência não diz respeito a uma intuição "determinável" na qual eu estaria dado como objeto, mas a mim como instância "determinante" em todo conhecimento. ${ }^{7}$ Desse modo, é essencial para a concepção kantiana da autoconsciência distinguir entre o eu "como inteligência e sujeito pensante" e o eu "como objeto pensado" que, como tal, tem que ser dado na intuição interna. ${ }^{8}$ Cabe ressaltar que se trata aqui de uma distinção entre aspectos pelos quais estamos conscientes de nós mesmos, e não de uma distinção entre sujeitos numericamente distintos. Ao contrário: Kant enfatiza que o autoconhecimento exige a identidade do eu do qual há consciência como inteligência determinante com o eu que é dado como objeto determinável. ${ }^{9}$ No entanto, há uma diferença entre o conteúdo sob o qual um sujeito se entende na autoconsciência originária (eu como a instância pensante que 'determina' objetos) e o conteúdo 'objetual' sob o qual o sujeito se entende na medida em que possui consciência de si como objeto pensado e dado numa intuição.

6 Tal distinção implica que, em função do seu conteúdo, a autoconsciência originária não é uma consciência de si como objeto do conhecimento. Nesse ponto consiste o argumento decisivo de Kant em favor da tese de que a autoconsciência originária não pode ser um conhecimento de si. Na autoconsciência originária, não estou consciente de mim como objeto 'determinável' que esteja dado numa intuição, mas como a instância 'determinante' em todo conhecimento, a aplicação das categorias às intuições dadas sendo a fundamental atividade dessa instância. Segundo Kant, tal autoconsciência é um produto do pensamento espontâneo. Ela é fruto de nossa capacidade de nos tornamos conscientes de nós mesmos como sujeito pensante e unificador em qualquer estado representacional. É nesse sentido que Kant diz que "o Eu penso deve poder acompanhar todas as minhas representações". 
7 Cabe destacar que, segundo a concepção kantiana, a autoconsciência originária é uma consciência de si como inteligência e sujeito pensante. Pode-se falar aqui de um 'como' não-objetual, que não diz respeito ao conteúdo de um conhecer-a-si-mesmo como um objeto que possui determinadas propriedades (o 'como' do autoconhecimento), mas ao conteúdo de um pensamento que está voltado para a própria função epistêmicodeterminante em todo conhecimento. Na sua crítica da psicologia racional, Kant tematiza esse conteúdo como fundamento dos teoremas da psicologia racional que nela erroneamente é entendido como conteúdo de um autoconhecimento objetivo. O exemplo do Paralogismo da Substancialidade, que na segunda edição da Crítica é considerado o argumento fundamental da psicologia racional, mostra claramente que a reconstrução crítica da psicologia racional apresentada por Kant tem como ponto de partida um conteúdo da autoconsciência originária que é caracterizado por um 'como' não-objetual. Pois Kant reconhece que subjaz a esse paralogismo uma verdade sobre a autoconsciência que diz respeito ao seu conteúdo: na autoconsciência Eu penso, entendo a mim mesmo como possuindo sempre "o valor de um sujeito, de algo que não possa ser considerado apenas ligado ao pensamento como predicado" ${ }^{10}$. Assim, o si do qual se tem consciência na autoconsciência originária de fato possui um aspecto que caracteriza uma substância como tal: a não-predicabilidade, isto é, a impossibilidade de ser pensado como predicado a ser atribuído a algo outro. No entanto, esse fato não justifica a pretensão de conhecer a si mesmo como substância com base na consciência Eu penso. Pois o fato de que só posso estar consciente de mim como sujeito lógico, e não como predicado de algo outro, deve-se ao fato de que na autoconsciência originária possuo a consciência não-objetual de mim como o "sujeito determinante da relação que constitui o juízo" (ibid.) que, como tal, aparece sempre no lugar do sujeito lógico de autoatribuições de pensamentos ou juízos. ${ }^{11}$ Com isso, passa-se do 'como' não-objetual envolvido na consciência Eu penso para a (suposta) determinação do próprio status metafísico como objeto do pensamento, ou seja, para o 'como' do autoconhecimento. No entanto, argumenta Kant, tal transição não pode ser válida. Somente o que é dado como objeto da intuição pode ser conhecido como substância. Portanto, só na medida em que referimo-nos a um objeto da intuição podemos inferir a substancialidade a partir da não-predicabilidade. ${ }^{12}$ Segundo Kant, a matéria é um objeto da intuição que conhecemos como substância. ${ }^{13} \mathrm{~A}$ consciência Eu penso, no entanto, apresenta a nãopredicabilidade como aspecto não-objetual do eu, ou seja, do eu pensado como sujeito determinante do conhecimento, e não como objeto dado na intuição.

8 Não é nosso objetivo investigar com mais pormenor a crítica kantiana do Paralogismo da Substancialidade. O que é importante aqui é destacar um elemento decisivo da análise kantiana desse argumento: a concepção do Eu penso como uma consciência nãoobjetual que possui um determinado conteúdo, isto é, no qual eu me apresento "como" possuindo determinadas características, no entanto, sem ser objeto para mim. Segundo Kant, o Paralogismo da Substancialidade baseia-se num aspecto do conteúdo do Eu penso como autoconsciência não-objetual que, como tal, é inegável, mas que não permite nenhuma conclusão 'objetual' sobre mim mesmo como objeto do conhecimento. Com isso, evidencia-se como origem do Paralogismo da Substancialidade uma ilusão transcendental, isto é: uma "necessidade subjetiva" do nosso pensamento (nesse caso: da nossa autoconsciência não-objetual) passa por uma "necessidade objetiva da determinação das coisas em si" ${ }^{14}$. Segundo Kant, a função do pensamento crítico na análise dos raciocínios da psicologia racional é justamente identificar tal 
ilusão como fonte da aparente força dos argumentos que são o fundamento dessa suposta ciência metafísica.

9 Ao distinguir a consciência de si como sujeito da consciência de si como objeto, Kant introduz a concepção de um tipo específico de consciência, tipo este que ele caracteriza como "mera consciência" de $\mathrm{si}^{15}$. Assim, mesmo que não seja seu objetivo na primeira Crítica desenvolver uma teoria da autoconsciência originária como questão de interesse próprio, Kant assume o ônus de elucidar minimamente a natureza peculiar dessa consciência pela qual ela difere de qualquer outro tipo de consciência, particularmente de qualquer consciência objetual. No entanto, na caracterização do conteúdo da autoconsciência pura Kant mantém o modelo representacionalista que tipicamente se aplica à consciência de objetos do conhecimento: a consciência de si como determinando objetos, o Eu penso, é caracterizado como "juízo" e a consciência do eu, contido nela, como envolvendo uma "representação", um "conceito" do eu ${ }^{16}$. Ao mesmo tempo, Kant reconhece que a concepção do Eu penso como consciência não-objetual o obriga a explicar a diferença entre a autoconsciência originária e o uso de representações, conceitos e juízos no conhecimento de objetos. Para tal, a estratégia de Kant é focalizar a função da representação do eu que seria diferente da função de representações que se referem a objetos do conhecimento: a representação do eu "não é tanto uma representação que distingue determinado objeto particular, mas uma forma da representação em geral, na medida em que deva chamar-se conhecimento ..." ${ }^{17}$. Desse modo, a consciência de si envolve a representação do eu, mas em vez de contribuir para o conteúdo do conhecimento, essa representação é constitutiva da 'forma' do conhecimento de objetos, ou seja, ao necessariamente poder acompanhar qualquer outra representação, ela é um princípio unificador da experiência, função esta que Kant focaliza na dedução transcendental das categorias. Assim, Kant mantém a caracterização da consciência do eu como "representação", no entanto, distinguindo-a de qualquer representação cuja função é a de representar objetos do conhecimento ao destacar seu papel formal e unificador.

10 No entanto, diante da sua peculiaridade funcional, em alguns momentos Kant parece distanciar-se da tese de que autoconsciência originária possa ser caracterizada por conceitos. Assim, ele diz que da representação eu "nem sequer se pode dizer que seja um conceito ...", pois ela é "apenas uma mera consciência que acompanha todos os conceitos"18. Não fica claro aqui qual a diferença que Kant vê entre uma "mera consciência" e um conceito propriamente dito. Mas independentemente disto, pode-se dizer que Kant percebe aqui que há um problema conceitual em torno da autoconsciência originária enquanto consciência não-objetual. Os conceitos que explicitam a estrutura representacional do conhecimento (os conceitos de representação e a própria noção de conceito) talvez não sejam apropriados para caracterizar a autoconsciência originária, por inevitavelmente entender a autoconsciência como consciência "de" algo num sentido que é próprio da referência a objetos do conhecimento. Não se pode dizer que Kant adotou o caminho de ir além da estrutura representacional da consciência para explicitar a natureza da autoconsciência pura. No entanto, tal passo pode ser atribuído a Fichte, a cuja concepção nos voltamos agora. ${ }^{19}$ 


\section{0 'como' não-objetual da autoconsciência na Doutrina da Ciência nova methodo}

11 Na Doutrina da Ciência nova methodo, a distinção entre o 'como' não-objetual da autoconsciência originária e o 'como' objetual do (auto-)conhecimento propriamente dito, que tem um papel decisivo na crítica kantiana da psicologia racional, está presente desde o início. ${ }^{20}$ Nessa exposição, tal distinção é empregada para apresentar a estrutura complexa da autoconsciência que, segundo Fichte, é a chave para a explicação filosófica dos aspectos teóricos e práticos da consciência. Assim, essa distinção aparece já na formulação do argumento através do qual Fichte pretende apontar para o ponto "no qual repousa minha doutrina inteira" ${ }^{21}$. A intenção de Fichte nesse argumento é mostrar que a autoconsciência não pode ter sua origem no ato pelo qual tornamo-nos objetos da nossa consciência. Para que possamos ter consciência de nós como objeto da consciência, é preciso que já exista alguma consciência de si como sujeito da mesma consciência, consciência esta que possui outra estrutura do que qualquer consciência de objetos. Essa autoconsciência originária Fichte chama de "autoconsciência imediata" e de "intuição intelectual". Fichte apresenta o passo decisivo do seu argumento da seguinte forma:

12 "Só tens consciência de ti mesmo, como aquele do qual há consciência, na medida em que tens consciência de ti mesmo, como aquele que tem consciência; mas, nesse caso, aquele que tem consciência se torna, novamente, aquele do qual há consciência, e tens, novamente, de tomar consciência daquele que tem consciência deste, e assim ao infinito: e, assim podes ver como chegarias a uma primeira consciência." 22

13 Explicitamente, Fichte distingue aqui duas formas da consciência de si 'como' algo que dizem respeito à respectiva função que é atribuída ao si consciente na sua relação com o estado da consciência: na primeira, o si é aquele "do qual há consciência", na segunda, ele é aquele "que tem consciência". Fichte deixa claro que a primeira forma da consciência de si é possibilitada pela segunda: na autoconsciência, sou aquele de que há consciência, mas para que o estado da consciência seja um caso de autoconsciência, é preciso que ele envolva a consciência de que aquele de qual há consciência é idêntico comigo como aquele que possui essa consciência, ou seja, comigo como sujeito desse estado da consciência. Com isso, Fichte focaliza a consciência de si como sujeito do estado atual da consciência como forma fundamental da autoconsciência. Ao mesmo tempo, Fichte aponta para um problema que enfrentamos se queremos entender a possibilidade dessa autoconsciência: para ter consciência de si como sujeito, é preciso ser, como sujeito, ao mesmo tempo "aquele do qual há consciência". No entanto, se aquele do qual há consciência como tal fosse sempre objeto da mesma consciência, eu não possuiria nessa consciência uma consciência de mim como sujeito do mesmo estado da consciência, mas apenas como seu objeto. $\mathrm{O}$ eu como sujeito de um estado da consciência estaria sempre, por assim dizer, fora do campo de visão do mesmo estado. Só através de uma reflexão de ordem superior sobre um estado da consciência seria possível tornar-se consciente de si como sujeito desse estado. Em tal reflexão, eu como sujeito de um estado da consciência tornar-me-ia objeto de uma consciência de ordem superior, meu papel como sujeito desse estado superior estando novamente fora do campo de visão desse mesmo estado.

14 Desse modo, surge um regresso infinito no qual sempre se precisa de mais um estado da consciência, a saber, de um estado que envolve uma reflexão de ordem superior, 
para que possa haver uma consciência de si como sujeito do estado atual. ${ }^{23}$ No entanto, argumenta Fichte, desse modo não se pode compreender a possibilidade da autoconsciência, na medida em que esta exige a consciência da identidade daquilo de que há consciência consigo como sujeito da mesma consciência. Como é possível possuir uma consciência de si como sujeito, e não apenas como objeto de um estado atual da consciência? O argumento fichtiano focaliza exatamente essa questão. E a conclusão disto, o ponto "no qual repousa minha doutrina inteira", é a tese de que tem que ser possível ser aquilo de que se tem consciência sem tornar-se objeto da mesma consciência. Somente sob esse pressuposto se entende a possibilidade de uma consciência de si como sujeito de um estado da consciência que está envolvida no mesmo estado, em vez de ser resultado de um ato reflexivo de ordem superior.

15 Desse modo, o ponto de partida da Doutrina da Ciência nova methodo é a tese de que é necessário supor uma autoconsciência não-objetual para se entender a possibilidade da consciência de si. Com isso, uma ideia que já está presente na crítica kantiana das pretensões da psicologia racional torna-se a chave para o entendimento da autoconsciência. Por isso, já no início da segunda exposição da Doutrina da Ciência Fichte introduz vários termos cuja função é chamar atenção para as características dessa autoconsciência originária, "sujeito-objeto" (Subjekt-Objekt), "autoconsciência imediata" (unmittelbares Selbstbewusstsein) e "intuição intelectual" (intellektuelle Anschauung) sendo os mais proeminentes. A função desses termos é expressar a ideia de que há uma consciência de si como sujeito que temos ao atuarmos como sujeito e não apenas através de uma reflexão de ordem superior sobre nossa atividade na qual esta se torna objeto da atenção. Tal noção de um 'como' não-objetual da autoconsciência encontra-se explicitamente na caracterização da intuição intelectual dada por Fichte na versão publicada do primeiro parágrafo da Doutrina da Ciência nova methodo: "A intuição de que se trata aqui é um pôr-se como pondo (algo objetivo, que também pode ser eu mesmo, como mero objeto), mas de nenhum modo, eventualmente, um mero pôr; pois com isso continuaríamos envolvidos na mesma impossibilidade, que acaba de ser indicada, de explicar a consciência." ${ }^{24}$

16 Há uma clara correspondência entre a caracterização da consciência de si como sujeito em Kant e a definição da intuição intelectual dada aqui por Fichte: Fichte fala da consciência de si como 'pondo' algo objetivo, Kant da consciência de si como 'determinando' objetos. E, como vimos acima, já segundo Kant tal concepção diz respeito a uma autoconsciência não-objetual. No entanto, cabe observar também que há uma diferença entre a concepção kantiana da consciência de si como sujeito e a de Fichte. Como vimos acima, Kant explica a diferença entre a autoconsciência originária e a consciência objetual ao destacar a função da representação 'eu': segundo Kant, a função dessa representação não é a de identificar o objeto de um conhecimento possível, mas a de servir como princípio formal e unificador das representações de objetos. Embora Kant em determinado momento questione se se pode falar de uma representação discursiva, ou seja, do "conceito" do eu, ele mantém a caracterização da autoconsciência originária como "representação" e, com isso, a ideia de que a autoconsciência originária, como a consciência propriamente objetual, ainda possui uma estrutura representacional. Em contraste, o argumento fichtiano estabelece a tese de que a autoconsciência originária é uma consciência 'de' si em sentido diferente de qualquer relação representacional. Pois a consciência de ser o sujeito de um estado representacional (a consciência de si como "pondo" algo objetivo), enquanto contido no mesmo estado, não difere do próprio ser-sujeito desse estado, ao contrário de uma 
representação que difere daquilo que ela representa. Fichte defende que a consciência de si como sujeito de um estado representacional está contida no exercício da atividade de "pôr" algo objetivo que é constitutivo do próprio ser-sujeito, não se devendo a uma reflexão de ordem superior sobre essa atividade. Por isso, o modelo representacional não se aplica à autoconsciência originária. ${ }^{25}$ Pela imediatez dessa consciência de si como sujeito, isto é, pela ausência da diferença representacional, Fichte a chama de "intuição"; mas pelo fato de a autoconsciência originária envolver o ato espontâneo que dá origem a consciência de si 'como' sujeito, ela precisa também ser caracterizada como "intelectual", no entanto, sem que ela envolva um conceito no sentido de uma representação discursiva. Assim, pode-se dizer que o núcleo da concepção fichtiana da intuição intelectual é a ideia do 'como' pré-reflexivo e não-objetual. ${ }^{26}$

Além de destacar o 'como' não-objetual como característica da intuição intelectual, na sua definição da intuição intelectual citada acima Fichte aponta para o fato de que a autoconsciência realiza-se também como consciência objetual: a atividade voltada para objetos da qual se tem uma consciência não-objetual pode também referir-se ao eu enquanto "mero objeto". Com isso, Fichte caracteriza o autoconhecimento propriamente dito, do qual Kant já disse que ele se refere ao eu "como objeto". Assim, também no que diz respeito à teoria do autoconhecimento pode-se dizer que a concepção fichtiana é devedora de uma reflexão sobre um aspecto já considerado por Kant. Na Doutrina da Ciência nova methodo, Fichte explicita a estrutura do autoconhecimento através da concepção do 'como' objetual da autoconsciência. No que segue, voltamo-nos a esse passo da segunda exposição da Doutrina da Ciência.

\section{3. "O eu põe-se como se pondo": o 'como' objetual da autoconsciência na segunda exposição da Doutrina da Ciência}

18 Já na exposição da Doutrina da Ciência de 1794/95 a concepção da autoconsciência objetual possui um papel importante. No quinto parágrafo da exposição, Fichte volta-se novamente para o conceito de eu, apresentando uma nova explicitação desse conceito que vai além da formulação dada no primeiro parágrafo. $\mathrm{O}$ eu, Fichte argumenta aqui, não pode ser caracterizado apenas por uma atividade autorreferencial (o 'pôr a si mesmo'), como na formulação dada no primeiro parágrafo. Pois é essencial para o eu que não possua tal atividade apenas do ponto de vista de um observador externo, mas que saiba dessa sua atividade essencial, ou seja, que possua um autoentendimento discursivo. Fichte denomina o ato no qual o eu se autocompreende de "reflexão". E justamente na caracterização do conteúdo da reflexão assim entendida aparece o 'como' em sentido objetual: “O eu não deve apenas pôr a si mesmo para uma inteligência qualquer fora dele, mas deve pôr-se para si mesmo; deve pôr-se como (als) posto por si mesmo ... Portanto o eu, tão certo quanto é um eu, tem de ter em si, incondicionalmente e sem nenhum fundamento, o princípio de refletir sobre si mesmo ..."27. O conteúdo da reflexão é um conteúdo conceitual que, de acordo como o princípio "Omnis determinatio est negatio", envolve o distinguir-se de algo outro e, com isso, a formação da noção do 'não-eu'. Assim, através da "lei da determinação daquilo sobre o qual se reflete" ${ }^{28}$, o distinguir-se do outro e, com isso, a noção de alteridade fica inserida na própria autoconsciência. Na medida em que é essencial para o eu 
desenvolver um autoentendimento reflexivo através do 'como' objetual-discursivo, evidencia-se com isso que há um "fundamento do sair de si mesmo" ${ }^{29}$ no próprio eu.

19 Na Doutrina da Ciência nova methodo, a concepção da reflexão, introduzida já no quinto parágrafo da Doutrina da Ciência de 1794/95, torna-se o decisivo instrumento teórico para a explicação da estrutura complexa da consciência. ${ }^{30}$ Nela, Fichte utiliza essa concepção já nos primeiros parágrafos da exposição, relacionando-a com a concepção da intuição intelectual, isto é, com a concepção do 'como' não-objetual que é o conteúdo da consciência originária de si como sujeito. Na medida em que o conteúdo originário da autoconsciência é não-objetual, o 'como' objetual da reflexão apresenta-se como resultado de uma auto-objetivação do eu. Assim, Fichte explicitamente caracteriza a reflexão com o ato pelo qual "o eu torna-se objeto da consciência" ${ }^{11}$. A formação de um auto-entendimento discursivo é uma conceitualização objetivante de um eu originariamente consciente de forma não-objetual, que deve preservar a sua espontaneidade como sujeito e ao mesmo tempo inseri-lo no contexto de um mundo objetivo que é entendido a partir de princípios discursivos.

Como reflexão, a autoconsciência é caracterizada pela ação recíproca entre as atividades "ideal" e "real", a segunda sendo a atividade própria que é objeto da intuição e do pensamento do mesmo sujeito. ${ }^{32}$ É uma tese central de Fichte na Doutrina da Ciência nova methodo que a atividade real do eu é essencialmente prática, isto é, ação livre que tem efeitos no mundo. Assim, a formula do 'como' objetual: "O eu põe a si mesmo como pondo a si mesmo" significa mais precisamente que o eu entende a si mesmo como "querendo" algo, o querer sendo a fundamental autoposição real. A concepção de si como agente livre e eficaz no mundo é o conteúdo primordial da relação reflexiva consigo como objeto real..$^{33}$ Desse modo, na Doutrina da Ciência nova methodo a teoria do 'como' objetual torna-se uma teoria sistemática da autoconsciência prática. ${ }^{34}$ Fichte explicita a estrutura da consciência de si como agente utilizando a distinção kantiana entre intuição e conceito: na sua autorreferência prática, o eu é dado para si mesmo como uma instância real, dotada de impulsos (intuição), relacionando-se ao mesmo tempo pelo seu pensamento com essa sua realidade ao adotar fins (conceito). Só os dois fatores juntos, ou seja, a 'ação recíproca' entre intuição e conceito, constituem o querer..$^{35}$

21 Não é o objetivo deste artigo investigar de modo pormenorizado a concepção fichtiana da autoconsciência prática. 0 resultado a ser destacado aqui é o seguinte: na Doutrina da Ciência nova methodo, a caracterização da autoconsciência segundo a qual "o eu se põe como pondo a si mesmo" de fato torna-se a concepção decisiva para a explicitação da estrutura da consciência a partir da autoposição do eu. Nela, a dualidade kantiana de intuição e conceito recebe uma nova interpretação, sendo aplicada à autoconsciência prática, ou seja, à dualidade de impulso e reflexão que essa autoconsciência envolve. No entanto, trata-se aqui do 'como' objetivante da reflexão do eu, e não da autoconsciência originária do eu que é caracterizada pelo 'como' não-objetual. Desse modo, Fichte desenvolve uma concepção complexa do 'como' da autoconsciência que abrange tanto seu conteúdo pré-reflexivo quanto o fundamental conteúdo objetual da autoconsciência como reflexão.

22 No entanto, cabe observar também que a concepção fichtiana do 'como' da autoconsciência não traz uma explicação da autoconsciência no sentido que está em foco na discussão atual, inspirada na leitura da segunda fórmula da autoconsciência proposta por Henrich. Pois as formulações de Fichte sempre já pressupõem que o 
sujeito entende a si mesmo como algo, sem explicar esse pressuposto. O 'como' da autoconsciência investigado por Fichte diz respeito ao conteúdo originário da autoconsciência. A questão de como o sujeito sabe que aquilo que ele entende de forma pré-reflexiva como sujeito e, na forma da consciência objetual, como si prático-volitivo, é ele mesmo, não é o foco da explicação fichtiana. ${ }^{36}$ Fichte parece considerar que esse aspecto não reside no conteúdo da autoconsciência, mas no modo como o sujeito está consciente do conteúdo pelo qual entende a si mesmo como algo. Tal posição estaria de acordo com a ideia de que a autoconsciência originária é mais uma modificação 'adverbial' do pensamento do que um ato particular ou um conteúdo da consciência, tese esta que está presente na discussão atual sobre a autoconsciência. ${ }^{37}$

\section{Conclusão}

23 Na Doutrina da Ciência nova methodo, Fichte atribui à autoconsciência a característica de ser uma consciência de si 'como' algo. Tal entendimento da autoconsciência é fundamental para a explicação da estrutura da consciência que nela é desenvolvida. É um mérito importante da leitura proposta por Henrich ter chamado a atenção para essa característica da segunda versão da Doutrina da Ciência. No entanto, mostrou-se que a exposição fichtiana do 'como' da autoconsciência possui uma complexidade que não é contemplada na leitura de Henrich. Pois o fato de que a autoconsciência essencialmente possui tal conteúdo para Fichte não significa que a consciência de si sempre já tem um conteúdo conceitual. Em vez disso, Fichte defende que ao autoentendimento discursivo subjaz a consciência de si como sujeito de qualquer posição de objetos, o 'como' envolvido nessa autoconsciência originária sendo essencialmente pré-reflexivo e nãoobjetual. Fichte exprime esse ponto ao atribuir a posição de si como pondo "algo objetivo" à intuição intelectual. ${ }^{38}$ É só com base nesse 'como' pré-reflexivo que a autoconsciência pode adotar a forma da consciência de si no sentido do autoentendimento discursivo. Nele, o sujeito torna-se objeto para si mesmo. E só no nível do 'como' objetual da reflexão aplica-se a distinção kantiana de intuição e conceito, que em Fichte recebe o sentido prático do entender-se como 'si real', dotado de impulsos e de vontade. Na apresentação de uma concepção sistemática dos níveis do 'como' da autoconsciência que abrange a autoconsciência pré-reflexiva e a reflexivoobjetual pode-se ver a principal contribuição para a teoria da autoconsciência contida na segunda exposição da Doutrina da Ciência, contribuição esta que é ainda relevante nos debates de hoje, mesmo que o quadro conceitual das discussões atuais não seja mais o que norteia a exposição fichtiana. ${ }^{39}$

\section{Bibliografia}

FICHTE, Johann Gottlieb, Gesamtausgabe der Bayerischen Akademie der Wissenschaften. Ed. Reinhard Lauth and Hans Gliwitzky. Stuttgart-Bad Cannstatt: Frommann-Holzboog, 1962 ff. (= GA).

(1984) A Doutrina-Da-Ciência de 1794 e outros Escritos, tradução de Rubens Rodigues Torres Filho, São Paulo: Abril Cultural. $(=D C)$. , (2004) "Resenha do Enesidemo". In: Beckenkamp, Joãosinho: Entre Kant e Hegel, Porto Alegre: EDIPUCRS 2004, pp. 74-99. (=RE). 


\section{NOTAS}

1. Fichtes ursprüngliche Einsicht é citado conforme a edição do texto em Henrich (2019), aqui: ver p. 9. No extenso texto de Henrich acrescentado em 2019, Der Einsicht nachdenken, cf. pp. 114/115 e $242 / 243$.

2. Ver Henrich (2019), p. 11; cf., em Der Einsicht nachdenken, pp. 105/106.

3. Ver Frank (2019), pp. 40 ss., especialmente pp. 41 e 49.

4. Ver Henrich (2019), pp. 21/22. Cf, em Der Einsicht nachdenken, pp. 78 e 247. No ensaio de 2019, Henrich aprofunda esse aspecto ao investigar a unidade de singularidade (autopresença) e generalidade (auto-entendimento conceitual) como característica fundamental da autoconsciência (ver especialmente pp. 108 ss., 115 e 230/231).
5. CRP, B 155.
6. Ver CRP, B 132.
7. Ver CRP, B 157/158.
8. CRP, B 155; cf. B 429.
9. Ver $C R P$, ibid.
10. CRP, B 407.

11. Cabe observar que esse passo da reconstrução kantiana do Paralogismo da Substancialidade envolve dois conceitos distintos, embora vinculados, de sujeito: a noção do sujeito cognoscente e a do sujeito em sentido lógico, ou seja, do sujeito de um juízo em contraposição ao seu predicado. Para uma discussão esclarecedora dos conceitos de sujeito que estão envolvidos na reconstrução kantiana da psicologia racional, cf. Rosefeldt (2000), especialmente pp. 33 ss..

12. Ver CRP, B 411.

13. Ver CRP, 278.

14. CRP, A $297=\mathrm{B} 353$.

15. CRP, A $346=\mathrm{B} 404$.

16. $C R P$, A $341=$ B 399; A 345/346 = B 404; B 408.

17. $C R P, \mathrm{~A} 346=\mathrm{B} 404$.

18. CRP, ibid.; cf. A 382. 
19. A respeito da oscilação de Kant na questão do conceito do eu, ver Rosefeldt (2000), p. 15 ss.. Rosefeldt não considera que a dificuldade em entender a autoconsciência originária conforme o modelo da representação possa ter sido um motivo pelo qual Kant em alguns momentos tenha negado o caráter conceitual da consciência do eu. Em contraste, Longuenesse observa que há um "desaparecimento da distinção" (vanishing distinction) entre o ato de pensar e a representação conceitual desse ato na consciência Eu penso enquanto consciência envolvida no próprio exercício da atividade de pensar. Segundo Longuenesse, em função disto a apercepção transcendental enquanto mera consciência da atividade da síntese pode ser comparada à autoconsciência "nãotética" de Sartre (ver idem, p. 92). A observação de Longuenesse parece-me no mínimo implicar que a consciência Eu penso envolve um 'conceito' do eu pensante num sentido peculiar que é caracterizado pela ausência da diferença entre representação e aquilo que é representado (ver Longuenesse (2017) p. 67, nota 12).

20. A Doutrina da Ciência nova methodo como um todo não foi publicada por Fichte. Os seguintes textos são as principais fontes a respeito da fundamentação fichtiana da filosofia na fase de 1796-1799, na qual Fichte, nos semestres de inverno, apresentou em Jena a segunda versão da Doutrina da Ciência: Versuch einer neuen Darstellung der Wissenschaftslehre, publicado em 1797/1798; o manuscrito de Halle (GA IV, 2, pp. 17-266); o manuscrito de Krause (GA IV, 3, pp. 323-535); Das System der Sittenlehre, publicado em 1798, e o manuscrito Neue Bearbeitung der Wissenschaftslehre (GA II, 5, pp. 331-402), embora o último em parte já seja um documento da transição para a Doutrina da Ciência de 1801/1802.

21. DC 181.

22. DC 181. Cf. GA IV, 2 (manuscrito de Halle), p. 30 e GA IV, 3 (manuscrito de Krause), p. 346.

23. $O$ fato de Fichte aqui formular o problema de um regresso infinito que surge na explicação da autoconsciência, se supormos que tal consciência é originariamente objetual, a fim de apontar para o ponto fundamental da sua doutrina, corrobora a tese de Henrich de que a descoberta da circularidade do modelo da reflexão foi um 'insight' decisivo para o pensamento de Fichte, mesmo que a formulação fichtiana do regresso não seja idêntica a nenhum dos dois regressos apresentados por Henrich no artigo de 1966.

24. DC 182.

25. Desse modo, o argumento de Fichte está em concordância com a intenção sistemática de ir além da estrutura da representação que caracteriza o projeto fichtiano desde o início, marcando a diferença com a 'filosofia elementar' de Reinhold que se baseava no princípio de que a consciência, inclusive a consciência de si, é essencialmente representação. Já na Resenha do Enesidemo de 1794, Fichte exprime esse ponto ao levantar a suspeita de que "tem de haver ainda para toda a filosofia ... um conceito superior ao da representação" (RE, p. 76).

26. Em Klotz (2002), explicitei a intuição intelectual como autoconsciência "não-intencional" para ressaltar o aspecto de que nela o eu não é objeto de uma representação (ver pp. 86 ss.). A interpretação apresentada no livro já envolvia a tese de que a intuição intelectual possui um conteúdo pré-representacional que Fichte exprime pela fórmula da posição de si 'como' sujeito da consciência intencional (ver especialmente p. 109/110). O objetivo deste artigo é focalizar esse aspecto para explicitar o sentido primordial da posição de si 'como' algo na segunda versão da doutrina da ciência, seguindo, por um lado, a tese de Henrich de que tal fórmula exprime uma tese central da segunda versão da Doutrina da Ciência e, por outro lado, destacando a diferença entre esse sentido primordial e o 'como' da representação discursiva focalizado por Henrich que, segundo a tese defendida aqui, pressupõe o 'como' pré-reflexivo.

27. DC 147.

28. DC 148.

29. DC 146 . 
30. Cf. Henrich 2019, p. 76, onde Henrich observa que a segunda fórmula já se encontra na Grundlage de 1794/95. No entanto, Henrich ressalta, só na Doutrina da Ciência nova methodo ela torna-se a ideia norteadora ("Leitgedanke") da filosofia de Fichte (ver também idem, p. 167).

31. GA IV/3, 352/53.

32. Ver GA IV, 2, pp. 44 ss., GA IV, 3, pp. 360 ss. e GA II, 5, pp. 357/358.

33. Ver GA IV, 2 (manuscrito de Halle), p. 45 ss., GA IV, 3 (manuscrito de Krause), p. 360 ss. e GA II, 5 (Neue Bearbeitung), pp. 357-358. Cf. Zöller 1998, especialmente pp. 3 s., 72 ss. e 86 ss.. Em Das System der Sittenlehre, Fichte exprime o caráter prático da reflexão pela seguinte tese: “Eu encontro a mim mesmo, como mim mesmo, somente querendo" (GA I, 5, p. 37 (tradução minha)).

34. Cf. Stolzenberg (1995).

35. A respeito da necessidade da consciência de impulsos para o agir livre, ver especialmente GA IV, 2 (manuscrito de Halle), pp. 60 ss. e GA IV, 3 (manuscrito de Krause), pp. 376 ss..

36. A formulação do 'de se constraint' dada por Manfred Frank exige uma concepção da autoconsciência que explicite justamente esse aspecto. Segundo a formulação de Frank, na autoconsciência o sujeito possui consciência de si 'como de si mesmo'. Ver Frank (2019), especialmente pp. 41 e 49.

37. U. Kriegel fala da autoconsciência "intransitiva" para exprimir tal concepção da autoconsciência.. Cf. Kriegel (2003).

38. Henrich reconhece que Fichte utiliza a concepção do 'como' pré-conceitual na sua filosofia tardia ao defender a tese de que o entender de uma imagem como imagem é uma condição fundamental do saber. No entanto, Henrich não considera que tal concepção esteja presente na explicação fichtiana da autoconsciência (ver (2019), p. 212).

39. Contribuições recentes para a teoria da autoconsciência defendem uma distinção semelhante entre níveis da autoconsciência. Um exemplo é a distinção introduzida por S. Lang entre "autoconsciência subjetivo-egológica" e "identificação autobiográfico-indexical" (ver Lang (2020), especialmente pp. 35 ss. e 175 ss.).

\section{RESUMOS}

In his groundbreaking article about Fichte's original insight, Dieter Henrich identifies in the second version of the Science of Knowledge an important step in the unfolding of Fichte's explanation of self-consciousness. Henrich holds that the formula, present in this version, "The I posits itself as positing itself" expresses the idea that self-consciousness cannot be understood as arising from a mere act of reflection in the sense of the act through which a subject turns itself an object for itself, but must envolve also the understanding of this act as a self-referential act. With this, Henrich claims, self-consciousness is understood to be a unity of intuition and concept, the concept yielding the knowledge (Wissen) of oneself "as" oneself without which the selfrepresenting act would not be self-consciousness in the proper sense. The article aims to show that in the second version of the Science of Knowedge the form of a consciousness of something 'as' something in fact plays an important role in Fichte's explanation of self-consciousness. However, it is argued that the primordial 'as' of self-consciousness there is understood to be prereflective, not yet involving any conceptual recognition through which the I turns itself an object of discursive knowledge. Thus, Fichte's conception of the 'as' of self-consciousness is more complex than that suggested by Henrich. It has its predecessor in Kant's distinction between "mere" self-consciousness and self-knowledge, involving both the non-objectual, pre-reflective 
'as' of self-consciousness, understood as intelectual intuition, and the objectual 'as' of selfknowledge.

ÍNDICE

Keywords: Self-consciousness, Reflection, Self-knowledge, Intellectual intuition

\section{AUTOR}

CHRISTIAN KLOTZ

Universidade Federal de Goiás 